\title{
Improving Surgical Care in Low- and Middle-Income Countries: A Pivotal Role for the World Health Organization
}

\author{
Stephen W. Bickler · David Spiegel
}

Published online: 30 October 2009

(c) The Author(s) 2009. This article is published with open access at Springerlink.com

\begin{abstract}
In response to increasing evidence that surgical conditions are an important global public health problem, and data suggesting that essential surgical services can be delivered in a cost-effective manner in low- and middleincome countries, the World Health Organization (WHO) has expanded its interest in surgical care. In 2004, WHO established a Clinical Procedures Unit within the Department of Essential Health Technologies. This unit has developed the Emergency and Essential Surgical Project (EESC), which includes a basic surgical training program based on the "Integrated Management of Emergency and Essential Surgical Care" Toolkit and the textbook "Surgery at the District Hospital." To promote the importance of emergency and essential surgical care, a Global Initiative for Emergency and Essential Care was launched in 2005. In what maybe the most important development, surgical care is included in WHO's new comprehensive primary health care plan. Given these rapid developments, surgical care at WHO may be approaching a critical "tipping point." Lobbying for a World Health Assembly resolution on emergency and essential surgical care, and developing "structured collaborations" between WHO and
\end{abstract}

\section{S. W. Bickler $(\square)$}

Division of Pediatric Surgery, Department of Surgery,

University of California at San Diego, 9500 Gilman Drive

\#0739, La Jolla, CA 92093-0739, USA

e-mail: sbickler@ucsd.edu

D. Spiegel

Children's Hospital of Philadelphia, Division of Orthopedic

Surgery, 2nd Floor Wood Building, 34th Street and Civic Center

Boulevard, Philadelphia, PA 19104, USA

D. Spiegel

The University of Pennsylvania School of Medicine,

Philadelphia, PA, USA various stakeholders are potential ways to ensure that the global surgery agenda continues to move forward.

\section{Introduction}

The World Health Organization (WHO) has traditionally not addressed surgical care, perhaps due to the inaccurate perception that surgery is a high-cost intervention benefitting only a limited segment of the population. A recent interest in surgery and anesthesia has been prompted by several factors. First, there is growing evidence that surgical conditions, especially injuries, obstetric emergencies, and congenital anomalies, are important public health problems [1, 2]. Second, it has been recognized that there are enormous gaps in access to life-saving and disability-preventing surgical services, particularly for the rural and/or marginalized populations in low- and middle-income countries (LMICs) [3-5]. Third, evidence is emerging to suggest that selected surgical services may compare favorably with many other health interventions in terms of cost effectiveness [6-8].

To better understand WHO's response to these findings and their role in promoting and developing surgical care in low- and middle-income countries, we review (1) general structure and function of the WHO, (2) current surgical programs at $\mathrm{WHO}$, (3) the evolving role of surgery in primary health care, and (4) WHO's pivotal role in developing surgery in LMICs.

\section{Structure and function of WHO}

The World Health Organization is a specialized agency of the United Nations (UN) that acts as a coordinating authority on international public health. Established in 1948, and 
headquartered in Geneva, Switzerland, the agency mandate is "the attainment by all peoples of the highest possible level of health" [9]. Its major task is to combat disease and to promote the general health of the people of the world.

The World Health Assembly is the decision-making body of WHO. Each year during May, representatives from the 193 member states meet in Geneva at the World Health Assembly to discuss health care priorities and to determine health policies. WHO's global influence is through their representatives working with the Ministries of Health in each country. The WHO is funded by contributions from member states and from outside donors. Major WHO projects are only possible when partnerships are created with outside agencies.

Surgical care within the WHO has been assigned to the Department of Essential Health Technologies (EHT). EHT's mandate is to assist countries to achieve a safe and reliable level of health services through it basic operational framework. To facilitate this work a Clinical Procedures Unit was established in 2004; this unit is responsible for ensuring efficacy, safety, and equity in provision of clinical procedures in surgery, anesthetics, obstetrics, and orthopedics. The target of this work has been the primary referral hospital where $90 \%$ of the world's populations receive their health care.

\section{Current surgical programs at WHO}

In response to the deficiencies in the capacity to deliver basic surgical services in LMICs, WHO launched the
Emergency and Essential Surgical Care Project in 2004. The Integrated Management of Emergency and Essential Surgical Care (IMEESC) toolkit [10], supplemented by the text "Surgical Care at the District Hospital" [11], was developed to provide a basic training package (Fig. 1). These teaching materials are based on WHO's minimum standards and technologies for emergency and essential surgical care, and designed to strengthen the delivery of surgical and anesthetic services at the primary-health facilities.

The IMEESC is a flexible template that can be adapted locally and incorporated into a variety of training programs. EESC promotes a horizontal approach, which allows it to cut across a variety of vertical initiatives (e.g., maternal health, Buruli ulcer, and male circumcision). Recognizing that trained surgeons will not be available to staff primary health facilities in LMICs in the foreseeable future, the target audience includes nonspecialist doctors, nurses, technicians, and paramedics. Training the trainers workshops are held in collaboration with WHO, the Ministries of Health, and both local and international partners. In addition to basic surgical skills, this diverse training package includes topics, such as team responsibility and organization, record keeping, basic anesthetic techniques, and resuscitation skills.

The Global Initiative for Emergency and Essential Surgery Care (GIEESC) was established in 2005 to promote the EESC program and to address deficiencies in the capacity for surgical care at primary referral level in LMICs [12]. The overall objective of GIEESC is to stimulate collaboration amongst organizations, agencies, and institutions involved in reducing death and disability from surgically
Fig. 1 Teaching tool for the Emergency and Essential Surgery Project. "Surgical Care at the District Hospital" and the "Integrated Management for Emergency \& Essential Surgical Care (IMEESC) toolkits" are available online (www.who.int/surgery)
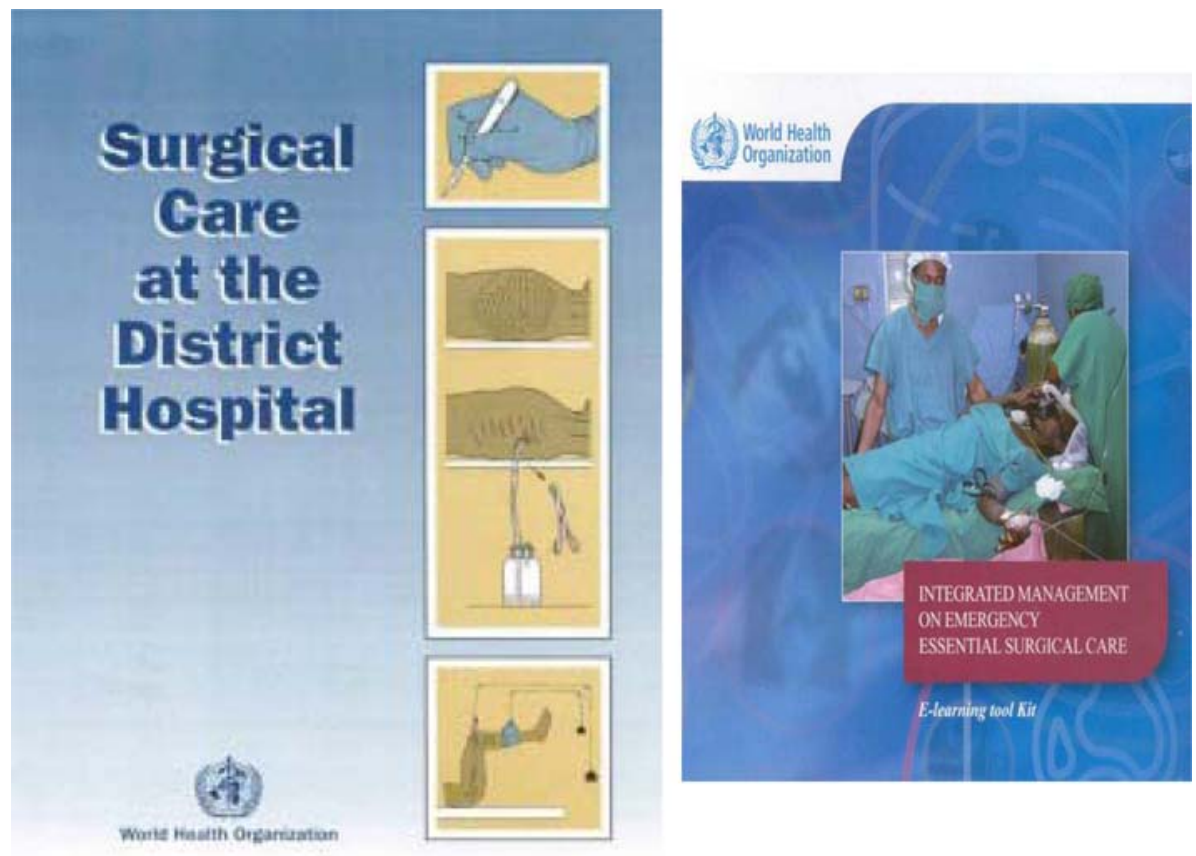
treatable conditions. The GIEESC secretariat is hosted at WHO headquarters in Geneva and meetings have been held in Geneva [13], Dar es Salaam, United Republic of Tanzania [14], and most recently in Ulaanbaatar, Mongolia (June 2009). GIEESC priorities have included advocacy, training and education, research, and the development of essential health technologies. Advocacy efforts have focused on the need to integrate EESC into health systems at the primary health care level, and this message has been asserted at three recent global health forums, including the Global Forum for Health Workforce (Uganda), the Primary Health Conference (Burkina Faso), and the Global Ministerial Forum on Research for Health (Mali). In addition, WHO has developed an interdepartmental working group on "Reaching Emergency and Essential Surgical Care to the Unreached" (WG-RESCU). As of June 2009, GIEESC workshops have been held in 32 countries, including 9 subSaharan African countries.

Characterizing the surgical capacity in low- and middleincome countries has been a research priority of GIESSC. To facilitate this research a situational analysis tool was developed to provide a simple, baseline assessment of infrastructure, physical resources and supplies, and human resources [15]. This tool was used to study surgical infrastructure and physical resources in eight LMICs (132 health facilities) and confirmed enormous deficiencies in the capacity to deliver surgery and anesthesia [16]. Recognizing that the questionnaire provides only a snapshot of the capacity for surgery at individual facilities, and that there is a need to develop a tool to monitor surgical capacity (as well as other health care services) at the facilities level, the situational analysis tool has been incorporated into the health facilities questionnaire for the WHO's Service Availability Mapping (SAM). The transfer of SAM technology to the country should allow ongoing monitoring of health services, including surgical capacity. Such data should be valuable for making decisions on resource allocation and policy development.

It also should be recognized that although the EESC project focuses on the delivery of surgical care, there are other projects at the WHO that are designed to improve the prevention and treatment of surgical diseases. The Department of Violence and Injury Prevention [17], along with partners, has developed "Guidelines for Essential Trauma Care," which provide both policy makers and caregivers with a flexible template from which to organize trauma care services at different level health facilities within the health system. The Patient Safety Division, through its "Safe Surgery Saves Lives" campaign [18], has been instrumental in promoting practices that limit medical errors and enhance patient safety. This group has developed and promoted a surgical checklist, which has been shown to reduce both mortality and morbidity, and should be implemented at all health facilities where surgery is performed [19]. Although this simple checklist will undoubtedly have a great impact, it will be of little value in facilities that lack the capacity to perform a surgical procedure-for example, due to lack of supplies or trained health workers.

\section{Evolving role of surgery in primary health care}

In what may be the most important development in surgery at WHO, surgical care has been included as a component the new comprehensive primary health care initiative. This new primary care initiative, described in the 2008 World Health Report [20], focuses on strengthening health systems through a series of reforms under the umbrella of primary health care. The driving force of these reforms is recognition that the traditional models of primary health care, as established by the Alta Ata Declaration 30 years ago, have failed. In sum, health systems have developed in directions that contribute little to equity and social justice and fail to get the best health outcomes for their money. The four major areas of this primary health care reform include universal coverage, service delivery, leadership, and public policy. A resolution reaffirming the importance of primary health care (WHA62.12) was recently approved at the 62nd World Health Assembly [21].

In the new conceptual model, primary health care is viewed as a hub of coordination within the health system, with surgical care as an essential component (Fig. 2). The importance here is that essential and emergency surgical care is clearly defined as primary health care. There also is growing interest in the concept that provision and maintenance of a quality surgical service may ultimately strengthen the capacity to deliver other health services, and even the entire health system.

\section{WHO's pivotal role in developing surgery in LMICs}

Given WHO's important role in developing global health policies, and it's influence at the country level through Ministries of Health, it is strategically placed to promote and develop safe and timely surgical care. The key question is how the global surgery community can work with WHO to ensure the surgical agenda moves forward. With this in mind, we propose two steps for those groups interested in developing emergency and essential surgical care in LMIC.

First, a World Health Assembly amendment confirming the critical role of emergency and essential surgery within the health system would establish basic surgery and anesthesia as critical components of population-based health care. This strategy has been used by the international 


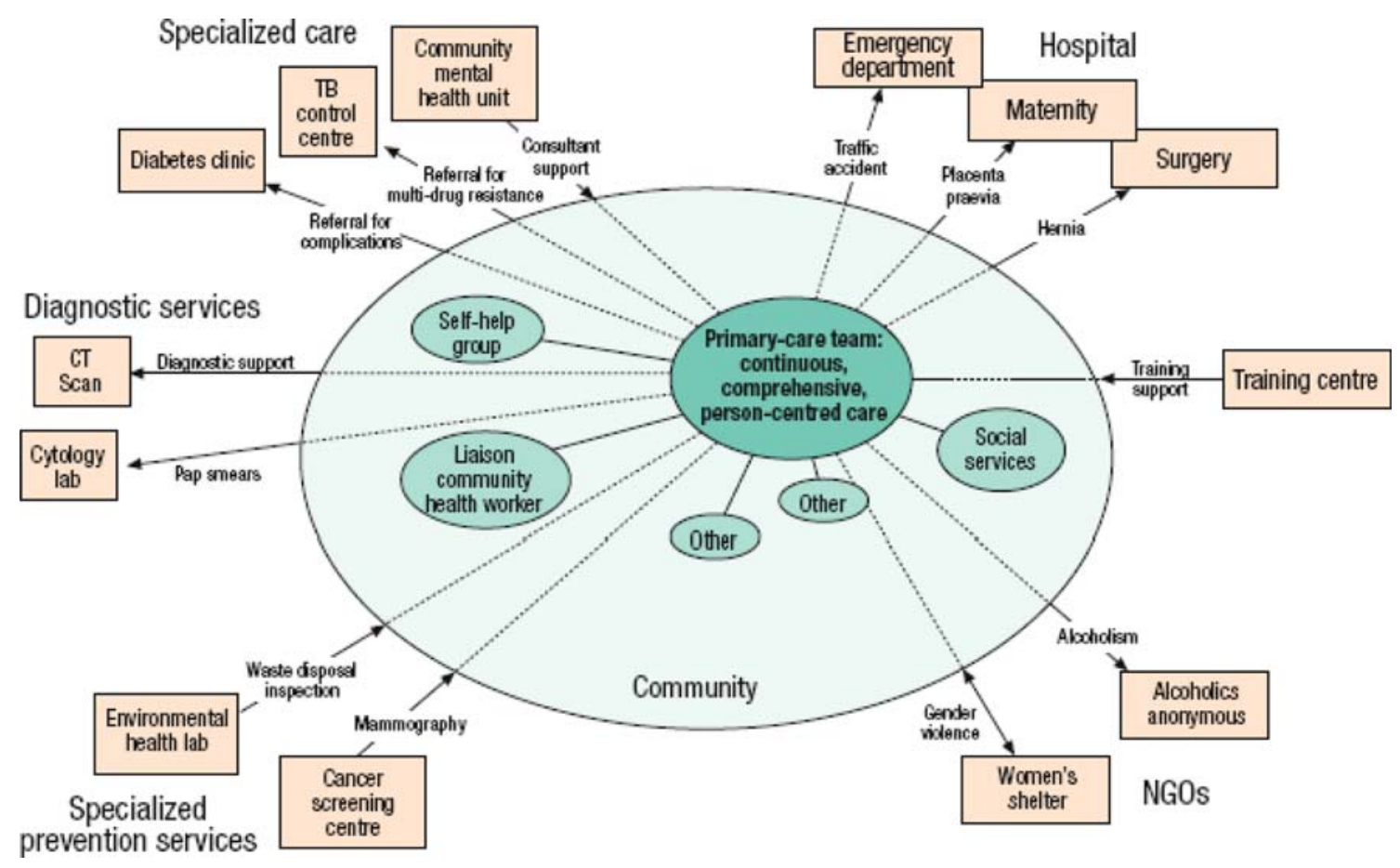

Fig. 2 Primary care as a hub of coordination: networking within the community served and outside partners. The Emergency Department, Maternity and Surgery are included as essential components. From the 2008 World Health Report [20]

trauma community to promote essential trauma care and has been immensely important in attracting additional resources [22]. Second, promoting "structured collaborations" between the WHO and other stakeholders (Fig. 3) could help mobilize resources to strengthen existing programs and develop new initiatives. Support through "structured collaborations" also could be in the form of sponsored fellowships at WHO, research, or involvement of EESC workshops in low- and middle-income countries.

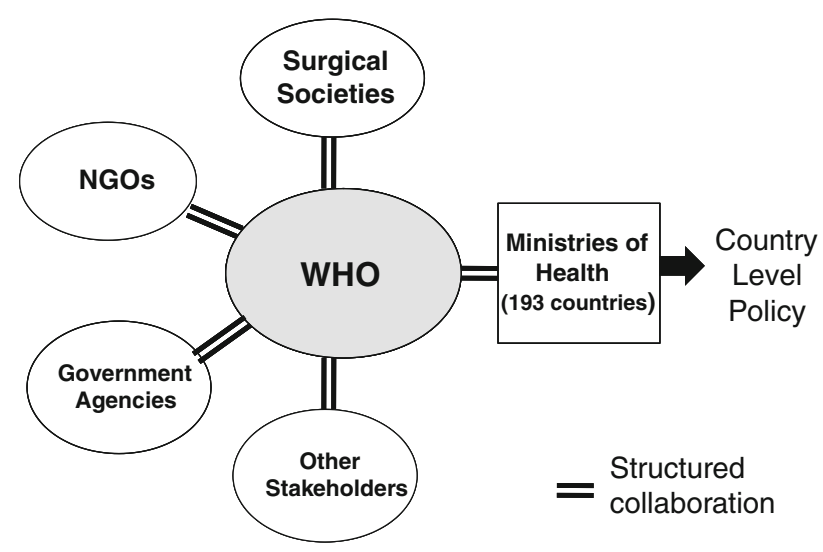

Fig. 3 Diagram depicting the manner in which WHO influences health care policy in low- and middle-income countries. By forming "structured collaborations" with WHO international surgical societies and other stakeholders could work together to promote and development emergency and essential surgical care
In summary, surgical programs at WHO are rapidly evolving due to increasing recognition that surgical conditions are an important public health problem, and knowledge that surgery may be an efficacious and costeffective addition to a basic package of health services. Although badly under-resourced at present, surgery seems to be approaching a critical "tipping point" where surgery's role could expand even further. It is an opportune time for international surgical groups to form partnerships with WHO to ensure that this agenda will be successful.

Open Access This article is distributed under the terms of the Creative Commons Attribution Noncommercial License which permits any noncommercial use, distribution, and reproduction in any medium, provided the original author(s) and source are credited.

\section{References}

1. Debas H, Gosselin R, McCord C, Thind A (2006) Surgery. In: Jamison D (ed) Disease control priorities in developing countries, 2nd edn. Oxford University Press, New York

2. Ozgediz D, Jamison D, Cherian M, McQueen K (2008) The burden of surgical conditions and access to surgical care in low- and middle-income countries. Bull World Health Organ 6:646-647

3. Weiser TG, Regenbogen SE, Thompson KD et al (2008) An estimation of the global volume of surgery: a modeling strategy based on available data. Lancet 372:139-144

4. Spiegel DA, Gosselin RA (2007) Surgical services in low-income and middle-income countries. Lancet 370:1013-1015 
5. Bickler S, Spiegel D (2008) Global surgery-defining a research agenda. Lancet 372:90-92

6. McCord D, Chowdhury Q (2003) A cost-effective small hospital in Bangladesh: what it can mean for emergency obstetric care. Int J Gynaecol Obstet 81:83-92

7. Gosselin RA, Amardeep Thind A, Bellardinelli A (2008) Cost/ DALY Averted in a small hospital in Sierra Leone: what is the relative contribution of different services? World J Surg 30:505511

8. Gosselin RA, Heitto (2008) Cost-effectiveness of a district trauma hospital in Battambang, Cambodia. World J Surg 32: 2450-2453

9. Constitution of the World Health Organization. World Health Organization. http://www.who.int/entity/governance/eb/who_con stitution_en.pdf. Accessed 14 June 2009

10. Integrated Management of Emergency and Essential Surgical Care. World Health Organization. http://www.who.int/surgery/ publications/imeesc/en/index.html. Accessed 14 June 2009

11. Surgical Care at the District Hospital (2003) World Health Organization, Geneva. www.who.int/surgery/publications/scdh_ manual. Accessed 14 June 2009

12. Global Initiative of Emergency and Essential Surgical Care (GIEESC) http://www.who.int/surgery/globalinitiative/en/. Accessed 14 June 2009

13. WHO meeting towards a Global Initiative for Emergency and Essential Surgical Care (GIEESC) (2005) Geneva, Switzerland. http://www.who.int/entity/surgery/mission/GIEESC2005_Report. pdf. Accessed 14 June 2009

14. WHO meeting on a Global Initiative for Emergency and Essential Surgical Care (GIEESC) (2007) Dar Es Salaam, United
Republic of Tanzania. http://www.who.int/surgery/education training/GIEESC_TanzaniaReportApril08.pdf. Accessed 14 June 2009

15. WHO situational analysis tool. www.who.int/entity/surgery/publi cations/QuickSitAnalysisEESCsurvey.pdf. Accessed 14 June 2009

16. Kushner AL, Cherian MN, Noel L, Spiegel DA (2009) Addressing the millennium development goals from a surgical perspective: essential surgery and anaesthesia in eight low and middle income countries. Arch Surg (in press)

17. WHO Violence and injury prevention. www.who.int/violence injury_prevention/. Accessed 14 June 2009

18. WHO Safe surgery saves lives. www.who.int/patientsafety/ safesurgery/en/. Accessed 14 June 2009

19. Haynes AB, Weiser TG, Berry WR, Lipsitz SR, Breizat AH, Dellinger EP, Herbosa T, Joseph S, Kibatala PL, Lapitan MC, Merry AF, Moorthy K, Reznick RK, Taylor B, Gawande AA, SafeSurgerySavesLivesStudy Group (2009) A surgical safety checklist to reduce morbidity and mortality in a global population. N Engl J Med 360(5):491-499

20. World Health Report (2008) Primary care: now more than ever. World Health Organization, Geneva. http://www.who.int/whr/ 2008/whr08_en.pdf. Accessed 14 June 2009

21. World Health Assembly resolution WHA62.12 Primary Health Care, including health system strengthening. http://www.15by 15 . org/wp-content/uploads/2009/05/primary_health_care_resolution_ wha.pdf. Accessed 14 June 2009

22. Mock C, Arafat R, Chadbunchachai W, Joshipura M, Goosen J (2008) What World Health Assembly Resolution 60.22 means to those who care for the injured. World J Surg 32(8):1636-1642 